\title{
Peranan Tim dalam Strategi Program Gerakan Kotak Infak Nahdlatul Ulama LAZISNU Padangsidimpuan
}

\author{
Nur Mutiah Tanjung1, Zakia Ananda Ritonga ${ }^{2}$ \\ 1,2,Institut Agama Islam Negeri Padangsidimpuan \\ JL. H.T. Rizal Nurdin Km 4,5 Sihitang Kota Padangsidimpuan _ Sumatera Utara
}

\begin{abstract}
Empowering zakat, infaq and alms is useful for overcoming the problem of poverty. The role of ZIS in overcoming social and economic problems is the background of the NU KOIN Movement to raise the standard of living of the community. This study uses a qualitative approach with the type of field research. Sources of data in the form of primary data and secondary data. Collecting data with the method of observation, interviews and documentation. The results of the study showed that the largest number of NU KOIN distribution teams were around the city of Medan with a total of 14 teams with the funds collected ranging from Rp. 156,501,700 and in Padangsidimpuan City with a total of 10 teams with a total fund of around Rp. 130,180,700. Meanwhile, in other districts of North Sumatra, the number of teams and funds collected was lower than the cities of Medan and Padangsidimpuan. The difference in the number of teams based on the area in the Padangsidimpuan district greatly affects the amount of zakat, infaq and shodaqoh funds collected. Strategy for implementing the NU KOIN Movement program at LAZISNU Padangsidimpuan by establishing and dividing regional coordinators, fundraising, clear and transparent bookkeeping, innovation and evaluation
\end{abstract}

Keywords : Zakat, Infaq, ZIS

\section{ABSTRAK}

Memberdayakan zakat, infaq dan sedekah berguna untuk mengatasi masalah kemiskinan. Peran ZIS untuk mengatasi masalah sosial dan ekonomi inilah yang melatarbelakangi Gerakan KOIN NU untuk mengangkat derajat hidup masyarakat. Penelitian ini menggunakan pendekatan kualitatif dengan jenis penelitian lapangan (field research). Sumber data berupa data primer dan data sukunder. Pengumpulan data dengan metode observasi, wawancara dan dokumentasi. Hasil penelitian diketahui bahwa jumlah tim penyebaran KOIN NU yang paling banyak berada di sekitar kota Medan dengan jumlah 14 tim dengan dana yang terhimpun berkisar Rp. 156.501.700 dan di Kota padangsidimpuan dengan jumlah 10 tim dengan jumlah dana berkisar Rp. 130.180.700. Sedangkan di KabupatenKota Sumatera Utara yang lain mempunyai jumlah tim dan dana yang terhimpun lebih rendah dari Kota Medan dan Padangsidimpuan. Adanya perbedaan jumlah tim berdasarkan luas wilayah pada kabupatenKota Padangsidimpuan sangat berpengaruh terhadap jumlah dana zakat, infaq dan shodaqoh yang terhimpun. Strategi pelaksanaan program Gerakan KOIN NU di LAZISNU Padangsidimpuan dengan cara membentuk dan membagi koordinator wilayah, fundraising, pembukuan yang jelas dan transparan, inovasi dan evaluasi

Kata Kunci : Zakat, Infaq, ZIS 
136 Peranan Tim dalam Strategi Program Gerakan Kotak Infak

Nahdlatul Ulama LAZISNU Padangsidimpuan

\section{PENDAHULUAN}

Kemiskinan merupakan masalah yang fundamental di seluruh negara dan agama islam menganjurkan untuk melaksanakan zakat, infaq, dan sedekah. Berdasarkan data Badan Pusat Statistik Provinsi Sumatera Utara yang menganut agama Islam sebanyak 63,36 persen, Kristen sebanyak 33,99 persen dimana Protestan sebanyak 26,66 persen dan Katolik sebanyak 7, 33 persen. Kemudian Budha sebanyak 2,43 persen, Konghucu sebanyak 0,11 persen, Hindu sebanyak 0,10 persen dan Parmalim sebanyak 0,01 persen.

Perkembangan agama Islam di Indonesia, semakin banyak memberdayakan zakat, infaq dan sedekah untuk pemberdayaan ekonomi untuk mengatasi masalah kemiskinan. LAZISNU Padangsidimpuan merupakan salah satu lembaga yang bergerak di bidang zakat, infaq dan sedekah. Lembaga pengelolaan zakat bertujuan untuk menghimpun, mengelola dan menyalurkan zakat, infaq dan sedekah sesuai yang berhak menerimanya (Maulana, 2020).

Peran ZIS untuk mengatasi masalah sosial dan ekonomi (kemiskinan) maka hal ini yang melatarbelakangi Gerakan KOIN NU agar mampu mengangkat derajat hidup masyarakat (APRIANI, n.d.).Gerakan KOIN NU merupakan pengumpul uang receh dengan menyediakan wadah berupa kaleng, kotak KOIN terbuat dari kayu dan kaca. Pengumpulan dana dilakukan 2 minggu sekali dan disalurkan kepada yang berhak menerima. Dana tersebut akan didisribusikan untuk kegiatan social keagamaan, ekonomi, pendidikan, renovasi dan juga kesehatan (Rosa, 2021). Untuk memenuhi kebutuhan tersebut maka dibuat tim untuk setiap wilayah dengan gerakan KOIN NU. Setiap tim mempunyai koordinator dalam pelaksanaan dan pengawasan program tersebut, kemudian dana dihimpun dan disalurkan. Semakin banyak tim, semakin banyak KOIN NU yang tersebar maka akan semakin banyak dana ZIS yang terkumpul (Nazila, 2019).

\section{METODE PENELITIAN}

\section{Jenis dan Pendekatan Penelitian}

Jenis Penelitian yang digunakan dalam penelitian ini adalah penelitian kualitatif deskriptif, yang mempunyai arti bahwa penelitian ini mengkaji dengan menggunakan cara kerja menjabarkan hasil penelitian berdasarkan penelitian dan pemaknaan terdata yang diperoleh cenderung data kualitatif, analisis data, bersifat induktif atau kualitatif, dan ini digunakan apabila data hasil penelitian tidak dapat diukur dengan angka atau dengan ukuran-ukuran lain yang bersifat eksak. Jenis penelitian dimaksudkan bahwa penelitian ini didasarkan pada system dan teknis pelaksanaan program KOIN NU, media sosial, rekening dan barcode pembayaran peduli dalam mengelola dana infaq guna kemaslahatan umat.

JISFIM: Journal of Islamic Social Finance Management, Volume 2, No 2 Tahun 2021 http://jurnal.iain-padangsidimpuan.ac.id/index.php/JISFIM 
Pendekatan yang digunakan dalam penelitian ini adalah pendekatan kualitatif mendefenisikan metodologi kualitatif sebagai prosedurpenelitian yang menghasilkan data deksriptif berupa kata-kata tertulis atau lisan dari orang-orang dan prilaku yang diamati.

Penelitian kualitatif adalah jenis penelitian yang mengeksplorasi dan memahami makna di sejumlah individu atau kelompok yang berasal dari masalah social. Penelitian kualitatif secara umum dapat digunakan untuk penelitian tentang kehidupan masyarakat, sejarah, tingkah laku, konsep atau fenomena, masalah social dan lain-lain. Salah satu alasan mengapa menggunakan pendekatan kualitatif adalah pengamatn peneliti dimana metode ini dapat menemukan dan memahami apa yang tersembunyi dibalik fenomena yang kadangkala merupakan sesuatu yang sulit untuk dipahami.

Jenis penelitian kualitatif yang digunakan oleh peneliti dalam penelitian ini adalah studi kasus. Studi kasus merupakn studi yang mengeksplorasi suatu kasus secara mendalam, mengumpulkan informasi seara lengkap dengn menggunakan berbagai prosedur pengumpulan data berdasarkan waktu yang telah ditentukan. Kasus ini dapat berupa suatu peristiwa, aktivitas, proses dan program (Sa'diyah, 2020).

\section{Unit Analisis}

Unit analisis mencakup sesuatu yang berkaitan dengan focus dan komponen yang akan diteliti. Unit analisis dalam suatu penelitian dapat berupa individu, kelompok, organisasi, benda dan waktu tertentu sesuai dengan focus permasalahannya. Unit analisis suatu penelitian dapat berupa lembaga organisasi atau dapat pula lingkup organisasi skala kesil serta terbatas.

Berdasarkan pernyataan diatas maka dalam penelitian ini mencakup lokasi penelitian yang berisi lingkup organisasi yang akan diteliti dan subjek penelitian sebagai individu atau kelompok yang ada dalam penelitian tersebut.

\section{Lokasi Penelitian}

Lokasi penelitian ini diambil adalah LAZISNU Padangsidimpuan jalan Masjid Raya Baru No. 24 a Komplek Masjid Agung Al Abror Kota Padangsidimpuan 22711.

\section{Subjek Penelitian}

Subjek penelitian yang dipilih dalam penelitian ini bertindak sebagai informan yang menjadi sumber inforasi bagi peneliti guna kebutuhan data penelitian yaitu Bapak Zulpan Harahap S.S, M.Pd, SM. Kom sebagai Ketua LAZISNU di Kota Padangsidimpuan. 
$\mathbf{1 3 8}$ P eranan Tim dalam Strategi Program Gerakan Kotak Infak

Nahdlatul Ulama LAZISNU Padangsidimpuan

\section{Data dan Jenis data}

Jenis data yang dimaksud adalah menyangkut informasi yang dapat berupa memperkaya dan informasi tentang permasalahan yang menjadi perhatian peneliti. Sumber yang diharapkan mampu menyediakan informasi yang diperlukan dalam penelitian ini yaitu

\section{Data Primer}

Data yang diperoleh atau dikumpulkan langsung dari narasumber yang berada di LAZISNU Padangsidimpuan, data tersebut secara langsung berhubungan dengan obyek penelitian dan mampu memberikan informasi yang dibutuhkan dalam penelitian ini, melalui wawancara yang berkaitan dengan permasalahan yang diteliti. Data primer antara lain : catatan hasil wawancara, dan data-data mengenai penelitian (Nasrudin, 2017).

\section{Data Sekunder}

Data yang diperoleh peneliti dari sumber yang ada. Dapat berupa bukti pencatatan, pembukuan, dan kumpulan data yang akan diteliti sebagai penguat dan pendukung .

\section{Teknik Pengumpulan}

Tekhnik pengumpulan data merupakan faktor penting demi keberhasilan penelitian. Hal ini berkaitan dengan bagaimana cara mengumpulkan data, siapa sumbernya, dan apa alat yang digunakan. Jenis sumber data adalah mengenai dari mana data diperoleh. Apakah data diperoleh dari sumber langsung (data primer) atau data diperoleh dari sumber tidak langsung (data sekunder).

\section{Teknik Analisi Data}

Analisis data merupakan penguraian data dalam bentuk kalimat yang tersusun secara sistematis, jelas dan terperinci yang kemudian diinterreasikan untuk memperoleh suatu kesimpulan.

Metode yang dipergunakan dalam penelitian ini adalah analisis kualitatif deskriptif, yakni memberikan pengertian terhadap data yang dimaksud menurut kenyataan yang diperoleh dilapangan dan disusun serta diuraikan dalam bentuk kalimat per kalimat dimulai dai tahapan pengumpulan data dilanjutkan dengan reduksi data, display data dan tahapan terakhir penarikan kesimpulan dan verifikasi. 


\section{Uji Keabsahan Data}

Keabsahan data dalam penelitian kualitatif merupakan salah satu bagian yang sangat penting untuk mengetahui derajat kepercayaan dari hasil penelitian yang telah dilakukan dengan menggunakan teknik triangulasi. Dalam pengumpulan data, maka data yang diperoleh akan lebih konsisten sehingga menjadi suatu data yang valid dan bisa dipertanggungjawabkan.

Agar penelitian dapat dipertanggung jawabkan maka diperlukan pengecekan dan apakah data yang disajikan valid atau tidak maka diperlukan teknik keabsahan atau kevalidan data.

Untuk memeriksa keabsahan data dalam penelitian ini, penelitian menggunakan teknik triangulasi. Triangulasi diartikan sebagai teknik pengumpulan data yang bersifat menggabungkan data dari berbagai teknik pengumpulan data dan sumber data yang telah ada. Dalam penelitian ini menggunakan 2 macam triangulasi yaitu; Triangulasi teknik adalah peneliti menggunakan teknik pengumpulan data yang berbeda-beda untuk mendapatkan data dari sumber data yang sama; Triangulasi Sumber digunakan untuk mendapatkan data dari sumber yang berbeda-beda denga teknik yang sama.

\section{HASIL DAN PEMBAHASAN}

NU CARE - LAZISNU

NU CARE-LAZISNU adalah rebranding dan/atau sebagai pintu masuk agar masyarakat global mengenal Lembaga Amil Zakat, Infak, dan Sedekah Nahdlatul Ulama (LAZISNU). NU CARE-LAZISNU berdiri pada tahun 2004 sebagai sarana untuk membantu masyarakat, sesuai amanat muktamar NU yang ke-31 di Asrama Haji Donohudan, Boyolali, Jawa Tengah. NU CARE secara yuridis-formal dikukuhkan oleh SK Menteri Agama No. 65/2005 untuk melakukan pemungutan Zakat, Infak, dan Sedekah kepada masyarakat luas (ISLAM, n.d.).

NU CARE-LAZISNU merupakan lembaga nirlaba milik perkumpulan Nahdlatul Ulama (NU) yang bertujuan, berkhidmat dalam rangka membantu kesejahteraan umat; mengangkat harkat sosial dengan mendayagunakan dana Zakat, Infak, Sedekah serta Wakaf (ZISWAF) (DAAIM, 2020).

Sejarah dan Perkembangan

1. 2004 (1425 Hijriyah) Lembaga Amil Zakat, Infak, dan Sedekah Nahdlatul Ulama (LAZISNU) lahir dan berdiri sebagai amanat dari Muktamar Nahdlatul Ulama (NU) yang ke-31, di Asrama Haji Donohudan, Boyolali, Jawa Tengah. Ketua Pengurus Pusat (PP) LAZISNU yang pertama adalah Prof. Dr. H. Fathurrahman Rauf, M.A., yakni seorang akademisi dari Universitas Islam Negeri (UIN) Syarif Hidayatullah, Jakarta.

JISFIM: Journal of Islamic Social Finance Management, Volume 2, No 2 Tahun 2021 http://jurnal.iain-padangsidimpuan.ac.id/index.php/JISFIM 
140| Peranan Tim dalam Strategi Program Gerakan Kotak Infak Nahdlatul Ulama LAZISNU Padangsidimpuan

2. 2005 (1426 Hijriyah) secara yuridis-formal LAZISNU diakui oleh dunia perbankan dan dikukuhkan oleh Surat Keputusan (SK) Menteri Agama No.65/2005.

3. 2010 (1431 Hijriyah) pada Muktamar Nahdlatul Ulama (NU) ke-32, di Makassar, Sulawesi Selatan, memberi amanah kepada KH. Masyhuri Malik sebagai Ketua PP LAZISNU dan menggantikan Prof. Dr. H. Faturrahman Rauf, MA. KH. Masyhuri dipercaya memimpin PP LAZISNU untuk masa kepengurusan 2010-2015. Hal itu telah diperkuat oleh SK Pengurus Besar Nahdlatul Ulama (PBNU) No.14/A.II.04/6/2010 tentang Susunan Pengurus LAZISNU periode 2010-2015.

4. 2015 (1436 Hijriyah) dengan berdasarkan Surat Keputusan Nomor: 15/A.II.04/o9/2015, Pengurus Pusat LAZISNU masa khidmat 2015-2020 diketuai oleh Syamsul Huda, SH.

5. 2016 (1437 Hijriyah) dalam upaya meningkatkan kinerja dan meraih kepercayaan masyarakat, NU CARE-LAZISNU menerapkan Sistem Manajemen ISO 9001:2015, yang dikeluarkan oleh badan sertifikasi NQA dan UKAS Management System dengan nomor sertifikat: 49224 yang telah diterbitkan pada tanggal 21 Oktober 2016. Dengan komitmen manajemen MANTAP (Modern, Akuntable, Transparan, Amanah dan Profesional).

Sampai saat ini, NU CARE telah memiliki jaringan pelayanan dan pengelolaan ZIS di 12 negara, di 34 provinsi, dan 376 kabupaten/kota di Indonesia. NU CARE sebagai lembaga filantropi akan terus berupaya untuk meningkatkan kepercayaan dari para donatur yang semua sistem pencatatan dan penyalurannya akan bisa dilihat secara real time melalui sistem IT (Ahmad, 2021).

\section{Defenisi ZIS (Zakat, Infaq dan Sedekah)}

Menurut bahasa,zakat berarti suci, baik, tumbuh dan berkembang. Zakat menurut istilah syariah yaiu mengeluarkan harta yang telah mencapai syarat nisab dan haul untuk diserahkan kepda penerimanya.

Infaq yang berarti mengeluarka sesuatu harta untuk kebaikan. Infaq menurut istilah syariah, infaq merupakan pengeluaran sebagian harta atau pendapatan atau penghasilan sesuai yang diperintahkan dalam agama islam. Perbedaan antara zakat dan infaq bahwa zakat memiliki syarat nisab dan haul sedangkan infaq tidak memilikinya. Zakat diberikan pada delapan asnaf sedangkan infaq diberikan kepada siapapun.

Shodaqoh/Sedekah adalah pemberian sesuatu yang bersifat kebaikan, baik berupa barang maupun jasadari seseorang kepada orang lain tanpa mengharapkan suatu imbalan apapun selain ridha Allah. Hukum dan ketentuan shodaqoh sama dengan ketentuan infaq. Hanya saja jika infak berkaitan dengan materi. Shodaqoh/sedekah memiliki arti yang lebih luas (Rafiqi, 
2019) Dengan demikian, zakat infak dansedekah dapat menjadi alternatif program pemerintah sebagaisumber dana untuk mengatasi kemiskinan (Roihanatasssa'adah, 2018).

\section{Penghimpunan dana}

Definisi Penghimpunan (Fundraising),Penghimpunan dalam dalam Kamus Besar Bahasa Indonesia (KBBI) adalah proses, cara, perbuatan mengumpulkan. Penghimpunan dana (fundraising) dapat pula diartikan sebagai proses mempengaruhi masyarakat baik perseorangan sebagai individu atau perwakilan masyarakat maupun lembaga agar menyalurkan dana atau sumber dayanya kepada sebuah organisasi atau lembaga (Hapsari, n.d.).

\section{Tujuan Penghimpunan (Fundraising)}

Ada beberapa hal yang menjadi tujuan dari fundraising bagi sebuah Lembaga Amil Zakat, Infak, dan Sedekah (LAZIS) adalah sebagai berikut; Pengumpulan dana. Pengumpulan dana mempunyai arti luas yaitu sumber daya (termasuk barang dan jasa) yang memiliki nilai materi dan dalam LAZIS ini sangat penting untuk mendukung program dan operasional yang telah dicanangkan; Penambahan jumlah muzakki dan donatur. LAZIS mempunyai data pertambahan muzakki dan donator sehingga akan mampu meningkatkan jumlah dana yang terhimpun; Meningkatkan citra LAZIS. Aktivitas fundraising yang dilakukan oleh sebuah LAZIS, baik langsung maupun tidak langsung akan membentuk citra lembaga itu sendiri akan membuat respon masyarakat positif dan akan semakin banyak menarik muzakki dan donator untuk ikut bergabung; Menjaga loyalitas muzakki dan donatur. LAZIS akan selalu menjaga loyalitas muzakki dan donatur merupakan tujuan yang tertinggi dan bernilai jangka panjang dengan memberikan bantuan sehingga akan memberikan kepuasan kepada muzakki dan donatur dengan pelayanan, program dan operasional LAZIS (Rafiqi, 2019).

\section{Gambaran Umum Sumatera Utara}

Sumatra Utara (disingkat Sumut) adalah sebuah provinsi di Indonesia yang terletak di bagian Utara Pulau Sumatra. Provinsi ini beribu kota di kota Medan, dengan luas wilayah 72.981,23 km². Sumatra Utara merupakan provinsi dengan jumlah penduduk terbesar keempat di Indonesia, setelah provinsi Jawa Barat, Jawa Timur, dan Jawa Tengah. Pada tahun 2020 penduduk Sumatra Utara berjumlah 15.136.522 jiwa, dengan kepadatan penduduk 207,40 jiwa $/ \mathrm{km}^{2}$

JISFIM: Journal of Islamic Social Finance Management, Volume 2, No 2 Tahun 2021 http://jurnal.iain-padangsidimpuan.ac.id/index.php/JISFIM 
142 P e ranan Tim dalam Strategi Program Gerakan Kotak Infak Nahdlatul Ulama LAZISNU Padangsidimpuan

Tabel 1. Jumlah penduduk dan luas wilayah di KabupatenKota di Sumatera Utara (Siregar et al., 2018)

\begin{tabular}{|c|c|c|c|c|}
\hline No & Kabupaten/Kota & $\begin{array}{c}\text { Pusat } \\
\text { Pemerintahan }\end{array}$ & $\begin{array}{c}\text { Luas Wilayah } \\
\qquad\left(\mathrm{km}^{2}\right)\end{array}$ & $\begin{array}{c}\text { Jumlah } \\
\text { Penduduk }\end{array}$ \\
\hline 1 & Kabupaten Asahan & Kisaran & $3.702,21$ & 706.283 \\
\hline 2 & Kabupaten Batubara & Limapuluh & 922,20 & 400.803 \\
\hline 3 & Kabupaten Dairi & Sidikalang & $1.927,80$ & 279.020 \\
\hline 4 & Kabupaten Deli Serdang & Lubuk Pakam & $2.241,66$ & 2.029 .308 \\
\hline 5 & $\begin{array}{l}\text { Kabupaten Humbang } \\
\text { Hasundutan }\end{array}$ & Dolok Sanggul & $2.335,33$ & 182.991 \\
\hline 6 & Kabupaten Karo & Kabanjahe & $2.127,00$ & 389.591 \\
\hline 7 & Kabupaten Labuhanbatu & Rantau Prapat & $2.156,02$ & 462.191 \\
\hline 8 & $\begin{array}{l}\text { Kabupaten Labuhanbatu } \\
\text { Selatan }\end{array}$ & Kota Pinang & 3.596 & 313.884 \\
\hline 9 & $\begin{array}{l}\text { Kabupaten Labuhanbatu } \\
\text { Utara }\end{array}$ & Aek Kanopan & $3 \cdot 570,98$ & 351.097 \\
\hline 10 & Kabupaten Langkat & Stabat & $6.262,00$ & $1.013 \cdot 385$ \\
\hline 11 & Kabupaten Mandailing Natal & Panyabungan & $6.134,00$ & 430.894 \\
\hline 12 & Kbupaten Nias & Gido & $1.842,51$ & 136.115 \\
\hline 13. & Kabupaten Nias Barat & Lahomi & 473,73 & 84.917 \\
\hline 14. & Kabupaten Nias Selatan & Teluk Dalam & $1.825,20$ & 308.281 \\
\hline 15 & Kabupaten NIas Utara & Lotu & $1.202,78$ & 133.897 \\
\hline 16. & Kabupaten Padang Lawas & Sibuhuan & $3.892,74$ & 258.003 \\
\hline 17 & Kbupaten Padang Lawas Utara & Gunung Tua & $3 \cdot 918,05$ & 252.589 \\
\hline 18 & Kabupaten Pakpak Bharat & Salak & $1.218,30$ & $45 \cdot 516$ \\
\hline 19 & Kabupaten Samosir & Pangururan & $2.069,05$ & 123.789 \\
\hline 20 & Kabupaten Serdang Bedagai & Sei Rampah & $1.900,22$ & 123.789 \\
\hline 21 & Kabupaten Simalungun & Sipirok & $6.030,47$ & 275.098 \\
\hline 22 & Kabupaten Tapanuli Selatan & Sipirok & $6.030,47$ & 275.098 \\
\hline 23 & Kabupaten Tapanuli Tengah & Pandan & $2.188,00$ & 350.017 \\
\hline 24 & Kabupaten Tapanuli Utara & Tarutung & $3.791,64$ & 293.399 \\
\hline 25 & Kabupaten Toba & Balige & $2.328,89$ & 179.704 \\
\hline 26 & Kota Binjai & & 59,19 & 264 \\
\hline
\end{tabular}

JISFIM: Journal of Islamic Social Finance Management, Volume 2, No 2 Tahun 2021 http://jurnal.iain-padangsidimpuan.ac.id/index.php/JISFIM 


\begin{tabular}{|c|l|c|c|c|}
\hline 27 & Kota Gunung Sitoli & & 280,78 & 135.995 \\
\hline 28 & Kota Medan & & 265,10 & 2.210 .624 \\
\hline 29 & Kota Padangsidimpuan & & 114,66 & 209.796 \\
\hline 30 & Kota Pematangsiantar & 55,66 & 247.411 \\
\hline 31 & Kota Sibolga & 41,31 & 86.519 \\
\hline 32 & Kota Tanjungbalai & 107,83 & 167.012 \\
\hline 33 & Kota Tebing Tinggi & 31,00 & 156.815 \\
\hline
\end{tabular}

Jumlah tim dan dana yag terhimpun dari Gerakan KOIN LAZISNU Padangsidimpuan berdasarkan Kabupaten dan Kota di Sumatera Utara

Gerakan KOIN merupakan salah satu cara menghimpun dana yang akan disalurkan kepada masyarakat yang membutuhkan dengan memberdayakn sehingga akan mampu meningkatkan kesejahteraan masyarakat (Annisatry Lubis et al., 2020) . Penyebaran KOIN NU dilaksanakan di beberapa daerah Padangsidimpuann dan juga sampai di luar kota Padangsidimpuan dengan membagi tim untuk penghimpunan dan penyebaran KOIN NU di Sumatera Utara. Pada awal tahun 2020, KOIN NU dilaksanakan oleh tim 1 - 30, kemudian pada bulan September 2020 gerakan KOIN NU bertambah menjadi tim 31 - 65 dan sesuai dengan penambahan di beberapa daerah Sumatera Utara. Berawal dari jumlah tim yang berada disekitar Kota Padangsidimpuan dengan jumlah tim sebanyak 10 tim dan mempunyai KOIN NU sebanyak 977. Tim berikutnya berada di luar kota Padangsidimpuan sebanyak 2479 KOIN NU. Penyebaran KOIN NU pada tiap daerah atau wilayah sangat bermanfaat dalam menghimpun dana ZIS (Haslinda, 2020)

Tabel 2. Jumlah TimBerdasarkan Pembagian wilayah Kabupaten dan Kota di Sumatera Utara

\begin{tabular}{|c|l|c|}
\hline No & Kabupaten/Kota Sumatera Utara & Jumlah Tim \\
\hline 1 & Kabupaten Asahan & $\mathbf{1}$ \\
\hline 2 & Kabupaten Dairi & $\mathbf{1}$ \\
\hline 3 & Kabupaten Deli Serdang & $\mathbf{1}$ \\
\hline 4 & Kabupatem Humbang Hasundutan & $\mathbf{1}$ \\
\hline 5 & Kabupaten Karo & $\mathbf{1}$ \\
\hline 6 & Kabupaten Labuhanbatu & 3 \\
\hline 7 & Kabupaten Labuhanbatu Selatan & $\mathbf{1}$ \\
\hline 8 & Kabupaten Langkat & \\
\hline
\end{tabular}

JISFIM: Journal of Islamic Social Finance Management, Volume 2, No 2 Tahun 2021 http://jurnal.iain-padangsidimpuan.ac.id/index.php/JISFIM 
144 Peranan Tim dalam Strategi Program Gerakan Kotak Infak Nahdlatul Ulama LAZISN U Padangsidimpuan

\begin{tabular}{|c|l|c|}
\hline 9 & Kabupaten Mandailing Natal & 1 \\
\hline 10 & Kabupaten Padang Lawas & 1 \\
\hline 11 & Kabupaten Padanng Lawas Utara & 1 \\
\hline 12 & Kabupaten Samosir & 1 \\
\hline 13 & Kabupaten Simalungun & 5 \\
\hline 14 & Kabupaten Tapanuli Selatan & 1 \\
\hline 15 & Kabupaten Tapanuli Tengah & 1 \\
\hline 16 & Kabupaten Tapanuli Utara & 14 \\
\hline 17 & Kota Binjai & 10 \\
\hline 18 & Kota Medan & 2 \\
\hline 19 & Kota Padangsidimpuan & 1 \\
\hline 20 & Kota Pematangsiantar & 1 \\
\hline 21 & Kota Sibolga & 14 \\
\hline 22 & Kota Tebing Tinggi & 1 \\
\hline
\end{tabular}

Berdasarkan hasil wawancara dengan Bapak Zulpan Harahap, S.S, M.Pd, M.M, Pengurus Gerakan KOIN NU menyebarkan kotak kayu dan kotak kaca ke setiap warung warung seperti kios, rumah makan, restoran, counter HP, jual bahan bangunan, penginapan dan lain sebagainya yang ada di sekitaran Wilayah Kabupaten/Kota di Sumatera Utara. Pembagian tim masih sekitar 22 dari 33 Kabupaten/Kota di Sumatera Utara.

Jumlah tim penyebaran KOIN NU yang paling banyak berada di sekitar kota Medan dengan jumlah 14 tim, di Kota padangsidimpuan dengan jumlah 10 tim, di Kabupaten Tapanuli Selatan dengan jumlah 5 tim, Kabupaten Labuhan Batu Selatan dengan jumlah 3 tim, di Kota Pematangsiantar dnegan jumlah 2 tim dan kabupaten dan kota lainnya dengan jumlah 1 tim. Kerjasama tim setiap wilayah sangat membantu dalam menghimpun dana ZIS di Sumatera Utara.

JISFIM: Journal of Islamic Social Finance Management, Volume 2, No 2 Tahun 2021 http://jurnal.iain-padangsidimpuan.ac.id/index.php/JISFIM 


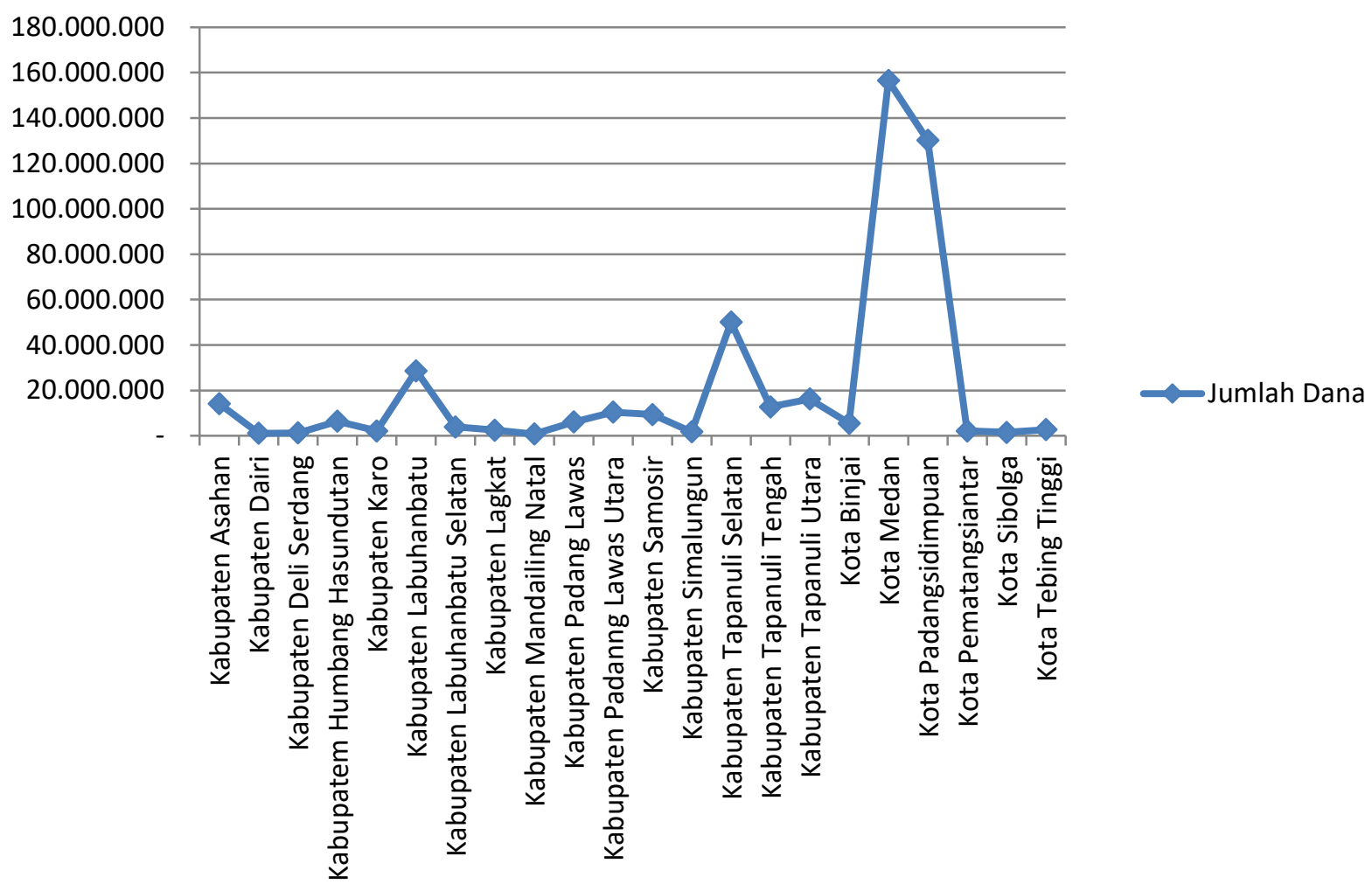

\section{Gambar 1. Jumlah Dana yang Terhimpun berdasarkan Kabupaten dan Kota di Sumatera Utara Selama Tahun 2020}

Jumlah dana yang terhimpun dengan gerakan KOIN NU, bahwa jumlah dana yang terhimpun yang paling tinggi di Kota Medan berkisar Rp. 156.501.700,oo dengan jumlah 14 tim dan di Kota Padangsidimpuan dengan jumlah dana berkisar Rp 130.180.700,oo dengan jumlah 10 tim. Sedangkan Kabupaten dan Kota yang lain memiliki dana yang terhimpun lebih rendah dengan jumlah tim yang relative lebih sedikit. Semakin banyak jumlah tim dalam suatu wilayah akan menghasilkan dana yang terhimpun semakin besar dan sebaliknya (Nazila, 2019). 
146|Peranan Tim dalam Strategi Program Gerakan Kotak Infak Nahdlatul Ulama LAZISNU Padangsidimpuan

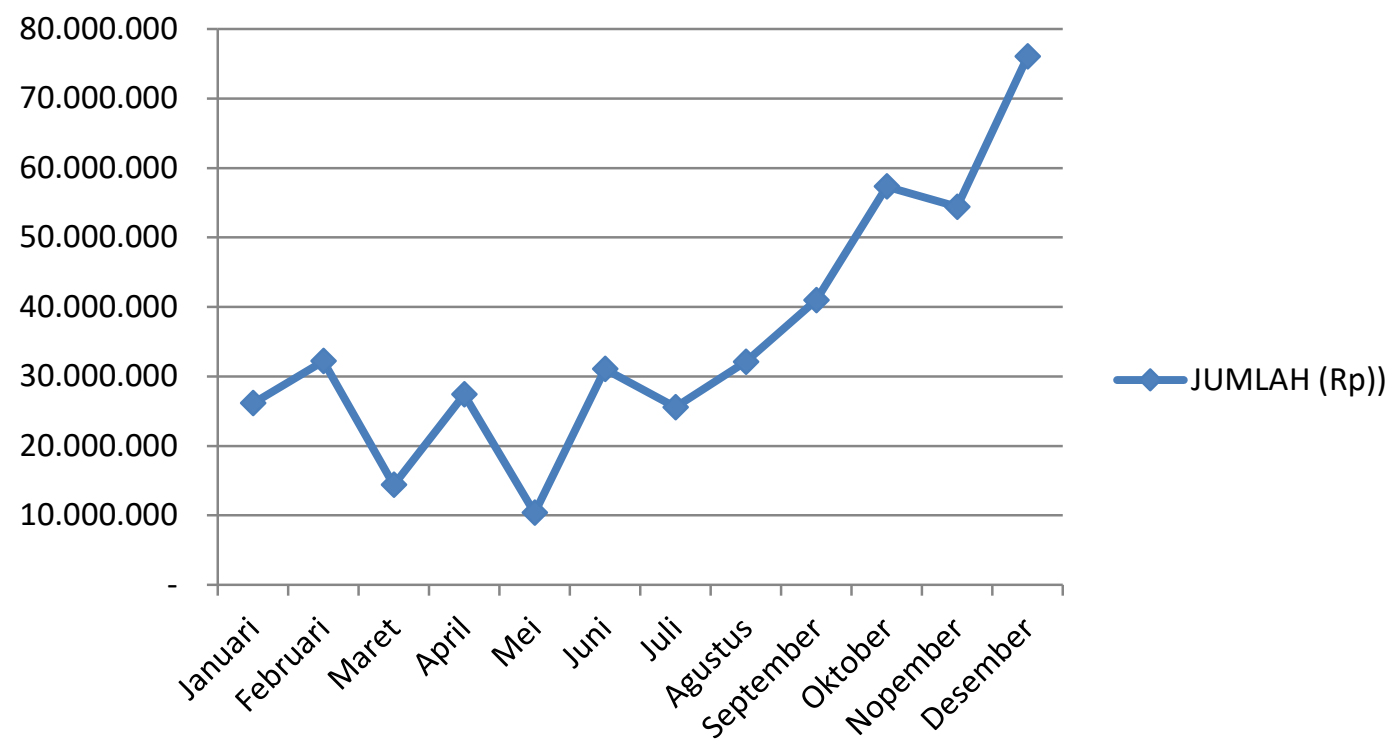

Gambar 2. Penghimpunan dana melalui Gerakan KOIN NU pada tahun 2020

Berdasarkan hasil wawancara dengan Bapak Zulpan Harahap, S.S.M.Pd.M.Kom dan data yang diperoleh bahwa pengumpulan KOIN NU sangat berpengaruh pada pengumpulan dana LAZISNU NU . Pengumpulan KOIN NU selama tahun 2020 yang paling rendah pada bulan Mei sebesar Rp. 10.353.500, oo dan paling tinggi pada bulan Desember 2020 berkisar Rp. 75.898.100,00.

Pada Bulan September 2020, adanya penambahan tim yang tinggi yaitu 13 tim dari 30 tim sebelumnya. Pada bulan berikutnya, juga adanya pertambahan tim lebih rendah dari penambahan tim bulan September Adanya penambahan tim pada pengumpulan KOIN NU sangat berpengaruh atas jumlah dana yang terhimpun (Wulandari, 2020).

Strategi pelaksanaan program Gerakan KOIN NU di LAZISNU Padangsidimpuan dengan cara membentuk dan membagi koordinator wilayah, fundraising, pembukuan yang jelas dan transparan, inovasi dan evaluasi. Semakin banyak gerakan KOIN NU akan semakin banyak dana yang terkumpulkan dengan pembagian wilayah dn coordinator yang jelas agar mencapai kepuasan dan pelayanan terhadap masyarakat untuk melakukan zakat, infaq dan shodaqoh sehingga dan dapat diberdayakan untuk mengurangi angka kemiskinan dn meningkatkan kesejahteraan masyarakat.

Faktor pendukung dari gerakan KOIN NU yaitu adanya manajemen sumber dana yang baik, manajemen pelaksanaan program yang baik dan anstusisme masyarakat yang tinggi. Sedangkan hambatannya yaitu kurangnya sumber daya manusia (Wiqoyati, 2019).

JISFIM: Journal of Islamic Social Finance Management, Volume 2, No 2 Tahun 2021 http://jurnal.iain-padangsidimpuan.ac.id/index.php/JISFIM 


\section{KESIMPULAN}

Kemiskinan merupakan masalah yang fundamental di seluruh negara dan agama islam menganjurkan untuk melaksanakan zakat, infaq, dan sedekah. Perkembangan agama islam di Indonesia, semakin banyak memberdayakan zakat, infaq dan sedekah untuk pemberdayaan ekonomi untuk mengatasi masalah kemiskinan. LAZISNU Padangsidimpuan merupakan salah satu lembaga yang bergerak di bidang zakat, infaq dan sedekah.

Gerakan KOIN merupakan salah satu cara menghimpun dana yang akan disalurkan kepada masyarakat. Penyebaran KOIN NU dilaksanakan di beberapa daerah Padangsidimpuan dan juga sampai di luar kota Padangsidimpuan dengan membagi tim untuk penghimpunan dan penyebaran KOIN NU di Sumatera Utara. Jumlah tim penyebaran KOIN NU yang paling banyak berada di sekitar kota Medan dengan jumlah 14 tim, di Kota padangsidimpuan dengan jumlah 10 tim, di Kabupaten Tapanuli Selatan dengan jumlah 5 tim, Kabupaten Labuhan Batu Selatan dengan jumlah 3 tim, di Kota Pematangsiantar dnegan jumlah 2 tim dan kabupaten dan kota lainnya dengan jumlah 1 tim.

Jumlah dana yang terhimpun dengan gerakan KOIN NU, bahwa jumlah dana yang terhimpun yang paling tinggi di Kota Medan berkisar Rp. 156.501.700,oo dengan jumlah 14 tim dan di Kota Padangsidimpuan dengan jumlah dana berkisar Rp 130.180.700,oo dengan jumlah 10 tim. Sedangkan Kabupaten dan Kota yang lain memiliki dana yang terhimpun lebih rendah dengan jumlah tim yang relative lebih sedikit. Semakin banyak jumlah tim dalam suatu wilayah akan menghasilkan dana yang terhimpun semakin besar dan sebaliknya. Semakin banyak gerakan KOIN NU akan semakin banyak dana yang terkumpulkan dengan pembagian wilayah dn coordinator yang jelas agar mencapai kepuasan dan pelayanan terhadap masyarakat untuk melakukan zakat, infaq dan shodaqoh sehingga dan dapat diberdayakan untuk mengurangi angka kemiskinan dn meningkatkan kesejahteraan masyarakat.

\section{SARAN}

Adapun saran-saran bagi Gerakan KOIN NU di LAZISNU daerah lain adalah membentuk pengurus Gerakan KOIN NU yang berdedikasi tinggi dan bersedia untuk terjun langsung ke lapangan untuk menyebarkan KOIN NU dan mengumpulkan hasil infaq warga secara rutin. Hal ini harus dilakukan karena bagaimanapun juga, kunci keberhasilan penghimpunan dana Gerakan KOIN NU terletak pada proses penyebaran KOIN NU dan pengumpulan dana infaq setiap 2 minggu sekali, melakukan pengawasan terhadap pelaksanaan program Gerakan KOIN NU; dan melakukan evaluasi terhadap pelaksanaan program Gerakan KOIN NU

JISFIM: Journal of Islamic Social Finance Management, Volume 2, No 2 Tahun 2021 http://jurnal.iain-padangsidimpuan.ac.id/index.php/JISFIM 
$\mathbf{1 4 8}$ P eranan Tim dalam Strategi Program Gerakan Kotak Infak Nahdlatul Ulama LAZISNU Padangsidimpuan

\section{DAFTAR PUSTAKA}

Ahmad, N. (2021). PEMBERDAYAAN EKONOMI MASYARAKAT MELALUI ZAKAT PRODUKTIF DI NU CARE-LAZISNU KABUPATEN BANYUMAS [PhD Thesis]. IAIN Purwokerto.

APRIANI, A. N. (n.d.). PERAN LAZISNU DALAM PENGENTASAN KEMISKINAN DI DAERAH KARAWANG.

DAAIM, M. (2020). Model Pengelolaan Zakat NU CARE-LAZISNU Tingkat Provinsi Jawa Tengah [PhD Thesis]. IAIN KUDUS.

Hapsari, P. S. (n.d.). Strategi Penghimpunan (Fundraising) Dana Zakat, Infak dan Sedekah (ZIS) Pada Lazis Griya Yatim dan Dhuafa (GYD).

Haslinda, H. (2020). Dakwah Melalui Gerakan Bersedekah Koin NU LAZISNU Kota Parepare [PhD Thesis]. IAIN Parepare.

ISLAM, J. S. D. K. (n.d.). SEJARAH LEMBAGA 'AMIL ZAKAT, INFAQ, DAN SHADAQAH NAHDLATUL ULAMA DAERAH ISTIMEWA YOGYAKARTA (LAZISNU DIY) TAHUN 2006- $2016 M$.

Maulana, R. R. (2020). Analisis Program Koin NU Peduli dalam pengelolaan infaq pada LAZISNU MWC Klojen Kota Malang [PhD Thesis]. Universitas Islam Negeri Maulana Malik Ibrahim.

Nazila, I. (2019). Strategi Program Gerakan Kotak Infaq Nahdlatul Ulama (Koin Nu) di Lazisnu Porong Kabupaten Sidoarjo [PhD Thesis]. UIN Sunan Ampel Surabaya.

Rafiqi, I. (2019). Strategi Fundraising Zakat Infaq Shadaqah di LAZISNU dan LAZISMU Kabupaten Pamekasan [PhD Thesis]. UIN Sunan Ampel Surabaya.

Roihanatasssa'adah, N. (2018). UPAYA PENINGKATAN PENGHIMPUNAN DANA ZAKAT, INFAK, DAN SEDEKAH (ZIS) OLEH LEMBAGA AMAL ZAKAT INFAK DAN SHADAQAH NAHDLATUL ULAMA (LAZISNU) KABUPATEN KUDUS [PhD Thesis]. IAIN KUDUS.

Rosa, S. Z. (2021). Pendistribusian Dana Zakat di LAZISNU Kecamatan Babadan Kabupaten Ponorogo (Analisis Manajemen Strategi) [PhD Thesis]. IAIN Ponorogo.

Sa'diyah, Y. H. (2020). Implementasi regulasi zakat terhadap kinerja amil zakat: Studi di kantor LAZISNU cabang Nganjuk [PhD Thesis]. Universitas Islam Negeri Maulana Malik Ibrahim.

Siregar, S. P., Wanto, A., \& Nasution, Z. M. (2018). Analisis Akurasi Arsitektur JST Berdasarkan Jumlah Penduduk Pada Kabupaten/Kota di Sumatera Utara. Seminar Nasional Sains Dan Teknologi Informasi (SENSASI), 1(1).

JISFIM: Journal of Islamic Social Finance Management, Volume 2, No 2 Tahun 2021 http://jurnal.iain-padangsidimpuan.ac.id/index.php/JISFIM 
Wiqoyati, Z. (2019). Strategi penghimpunan dana zakat infak dan sedekah (ZIS) pada lembaga amil zakat al Ihsan Jawa Tengah (LAZIS Jateng) cabang Pekalongan [PhD Thesis]. IAIN Pekalongan.

Wulandari, S. A. (2020). Analisa Strategi Pengumpulan dan Pendayagunaan Zakat Dampaknya Terhadap Peningkatan Muzakki (Studi Kasus Pada LAZISNU Jember) [PhD Thesis]. Institut Agama Islam Negeri Jember.

JISFIM: Journal of Islamic Social Finance Management, Volume 2, No 2 Tahun 2021 http://jurnal.iain-padangsidimpuan.ac.id/index.php/JISFIM 